\title{
A new species of the neopterygian fish Enchodus from the Duwi Formation, Campanian, Late Cretaceous, Western Desert, central Egypt
}

\author{
Waymon L. Holloway, Kerin M. Claeson, Hesham M. Sallam, Sanaa El-Sayed, Mahmoud Kora, Joseph \\ J.W. Sertich, and Patrick M. O'Connor \\ Acta Palaeontologica Polonica 62 (3), 2017: 603-611 doi:https://doi.org/10.4202/app.00331.2016
}

The neopterygian fish Enchodus was a widespread, speciose genus consisting of approximately 30 recognized species that were temporally distributed from the late Early Cretaceous through the Paleocene. Many Enchodus specimens are fragmentary cranial remains or isolated dental elements, as is the case for previously reported occurrences in Egypt. Here, we present the most complete specimen of Enchodus recovered from the Late Cretaceous of northeast Africa. The specimen was collected from the upper Campanian Duwi Formation, near the village of Tineida (Dakhla Oasis, Western Desert, Egypt). The new species, Enchodus tineidae sp. nov., consists of right and left dentaries, a partial ectopterygoid, and other cranial bones. The size of the specimen places it into the upper body-size range for the genus. The palatine tooth, an element often useful for diagnosing Enchodus to the species level, is not preserved, but a combination of other cranial characters supports the referral of this specimen to Enchodus. In particular, the dentary preserves three symphysial rostroventral prongs and two tooth rows, the lateral of which consists of small denticles, whereas the medial row comprises large, mediolaterally-compressed teeth. The rostral-most tooth exhibits the highest crown, whereas the rest of the teeth are of lower, variable crown heights. The eight robust, caudal-most medial-row teeth are distributed in a cluster pattern never before observed in Enchodus. Additionally, the dentary and preopercle are both without dermal ornamentation, and the mandibular sensory canal is closed. Phylogenetic analysis recovers this new species as the sister species to E. dirus from North America. Along with previously described materials from Israel, Jordan, Syria, Lebanon, Italy, Morocco, and Libya, this specimen represents a thirteenth species from the northwestern Tethyan geographic distribution of Enchodus.

Key words: Actinopterygii, Enchodus, Cretaceous, Campanian, Egypt.

Waymon L. Holloway [hollowaw@ohio.edu], Center for Ecology and Evolutionary Studies, Irvine Hall, Ohio University, Athens, Ohio 45701, USA; and Department of Biological Sciences, 107 Irvine Hall, Heritage College of Osteopathic Medicine, Ohio University, Athens, Ohio 45701, USA. Kerin M. Claeson [kerincl@pcom.edu 
], Department of Anatomy, Philadelphia College of Osteopathic Medicine, 4170

City Avenue, Philadelphia, Pennsylvania, 19131, USA. Hesham M. Sallam [sallam@mans.edu.eg

], Sanaa El-Sayed [muvp.eg@gmail.com], and Mahmoud Kora [kora@mans.edu.eg],

Mansoura University Vertebrate Paleontology Center, Department of Geology,

Faculty of Science, Mansoura University, Mansoura, 35516, Egypt. Joseph J. W.

Sertich [jsertich@dmns.org], Department of Earth Sciences, Denver Museum of

Nature \& Science, Denver, Colorado 802051, USA. Patrick M. O’Connor [oconnorp@ ohio.edu], Center

for Ecology and Evolutionary Studies, Irvine Hall, Ohio University, Athens, Ohio 45701, USA;

Department of Biomedical Sciences, 228 Irvine Hall, Heritage College of Osteopathic Medicine, Ohio

University, Athens, Ohio 45701, USA.

This is an open-access article distributed under the terms of the Creative Commons

Attribution License (for details please see creativecommons.org), which permits unrestricted use,

distribution, and reproduction in any medium, provided the original author and source are credited.

FoF Full text $(498.6 \mathrm{kB})$ ।

Fof Supplementary file $(59.8 \mathrm{kB})$ 